\title{
Safety-Zone Layout Design for a Floating LNG-Fueled Power Plant in Bunkering Process
}

\author{
Sung-In Park ${ }^{\mathrm{a}, \mathrm{b}}$, Su-Kyeong Kim ${ }^{\mathrm{a}, \mathrm{c}}$ and Jeom Kee Paik FREng ${ }^{\mathrm{a}, \mathrm{d}, \mathrm{e}^{*}}$ \\ ${ }^{a}$ Department of Naval Architecture and Ocean Engineering, Pusan National University, Busan, \\ Republic of Korea \\ ${ }^{\mathrm{b}}$ Department of the System Safety Research, Energy Technology R\&D Group, Korea Shipbuilding \\ \& Offshore Engineering Co., Ltd., Seoul, Republic of Korea \\ ${ }^{\mathrm{c}}$ The Medium Ship Design Centre, The Korea Research Institute of Ship and Ocean Engineering, \\ Busan, Republic of Korea \\ ${ }^{\mathrm{d}}$ The Korea Ship and Offshore Research Institute (Lloyd's Register Foundation Research Centre of \\ Excellence), Pusan National University, Busan, Republic of Korea \\ ${ }^{\mathrm{e}}$ Department of Mechanical Engineering, University College London, London, United Kingdom \\ *Corresponding author. Tel.: +82 51510 2429. Email address: jeompaik@gmail.com (J.K. Paik).
}

\begin{abstract}
The use of natural gas (NG) as an energy source is increasing. This paper studies the safety-zone layout design of a floating power plant fueled by NG. Hazards from the unwanted release of liquefied $\mathrm{NG}$ (LNG) in bunkering or NG in operation always exist, and it is thus important to reduce the associated risk to an acceptable level. One engineering technique used to reduce this risk involves the design of a safety zone to prevent and minimize exposures that may occur during unwanted release of LNG or NG. Industry practices are available for the design of the layout of such safety-zones, but their applicability to floating power plants is uncertain, and a more intuitive approach is required. The objective of this study is to discuss the challenges of establishing safety zones on floating power plants by reviewing and comparing existing industrial practices and to propose a hybrid approach for the design of a safety-zone layout. The applicability of the proposed hybrid approach is discussed with an applied example.
\end{abstract}

Keywords: LNG bunkering, floating LNG-fueled power plant, unwanted release of LNG, safety-zone layout design, hybrid approach.

\section{Introduction}


A floating LNG power plant has been developed as a new power supply solution for archipelago areas in Southeast Asia (Park et al., 2019). It is a unique system that is not accurately classified in the rules and regulations of maritime society, and thus a preliminary risk assessment study was required to allow the International Association of Classification Societies (IACS) to approve the feasibility of its conceptual design (ABS, 2017; DNVGL, 2017; LR, 2017). In this regard, a hazard identification (HAZID) study and a simple risk assessment were conducted, and the safety level of the initial plant design was verified (Park et al., 2019). At the assessment, unfavorable events were evaluated in association with minor or manageable risk, but some concerns remained about the possible effects of liquefied natural gas (LNG) or natural gas (NG) leakage during bunkering or during the plant's power generation process. Possible measures to resolve this problem were considered with additional safety barriers or a redesign of the plant's inherent safety features, including the development of a safety-zone layout.

A safety zone is set at a specific distance from an LNG bunkering facility and consists of one or several sections positioned between the facility and surroundings. The safety zone concept aims to ensure the safety of all life inside and outside the facility and has its origin in the treaty of the 1958 Convention on the Continental Shelf (UN, 1958). This treaty formulated the guidelines for the exploration of the continental shelf and its buried natural resources and recommended that a protective safety zone of up to $500 \mathrm{~m}$ should be established around exploring facilities for the protection of personnel. This concept has become firmly entrenched in industrial legislative societies and has provided a minimum protection for offshore installations, passing vessels, and all other neighboring activities around the world (IMO, 1977; IMO, 1989; NOPSEMA, 2016; UK Legislation, 1987).

Recently, an increasing number of marine systems have been developed in association with LNG usage (Schinas and Butler, 2016; Seo et al., 2016; Xu, 2015), and these are required to incorporate a safety zone to minimize the risks from undesirable leaks during bunkering operations (ISO, 2015b). The International Standard Organization (ISO) has defined the concept of LNG safety zones and introduced the engineering approaches for the design of these zones, in association with the necessary risk assessment methods (ISO, 2015a). Based on these guidelines, various countries and organizations have established their own codes and standards (Mokhatab et al., 2014) to explain the required layout design and operational procedures around an LNG bunkering site. Table 1 and Figure 1 illustrate an example of a detailed safety zone concept for an LNG bunkering site (ISO, 2015a; SGMF, 2018). 
Table 1. Definition of safety and security zones.

\begin{tabular}{|c|l|}
\hline Zone & \multicolumn{1}{c|}{ Definition } \\
\hline Safety zone & $\begin{array}{l}\text { The area around the bunkering station in which only dedicated and } \\
\text { essential personnel and activities are allowed during bunkering }\end{array}$ \\
\hline Security zone & $\begin{array}{l}\text { The area around the bunkering facility and ship in which ship traffic and } \\
\text { other activities are monitored (and controlled) to mitigate harmful effects }\end{array}$ \\
\hline $\begin{array}{c}\text { Marine (exclusion) } \\
\text { zone }\end{array}$ & $\begin{array}{l}\text { Definition of the marine exclusion zone is for each port to decide and } \\
\text { implement in port rules, based on specific port and ship studies. All ships } \\
\text { and bunker vessels must comply with these rules in the normal way }\end{array}$ \\
\hline External zone & $\begin{array}{l}\text { This zone is defined by the level of risk general members of the public } \\
\text { can be exposed to, based on local regulatory requirements }\end{array}$ \\
\hline
\end{tabular}

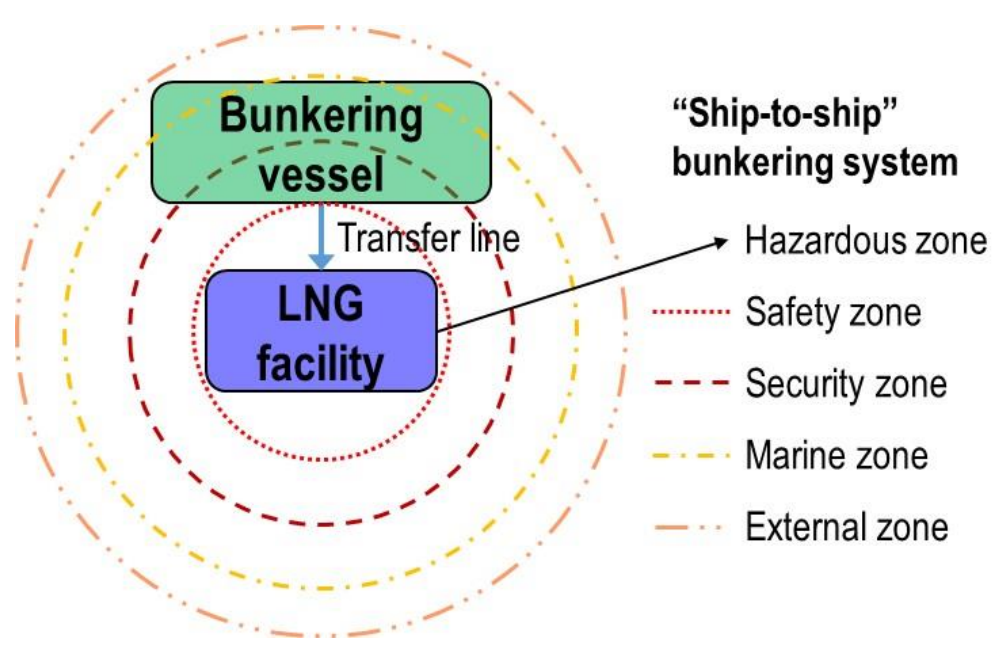

Fig. 1. Safety and other control zones for the LNG bunkering facility.

Most guidelines relevant to safety zone design are focused on a simple LNG transfer system and these are actively applied on the bunkering operation of various LNG fueled-ships in the maritime industry, but the applicability of these guidelines to the practical engineering required for more complex facilities such as a floating LNG power plant is limited. A new engineering approach is therefore presented in this study, which incorporates a more intuitive design for the safety zone layout of a floating LNG-powered plant.

This new approach aims to determine a more accurate safety zone boundary in consideration of the possible flammable leak event as early as possible to assist the operator in understanding its overall area of responsibility at an early stage of the project development. For this purpose, the most 
credible NG or LNG leak accident that might occur during power plant operation is identified, and the flammable limit range from this leakage is estimated with an analytical method. A literature review was also conducted on the engineering practices in this area, and the detailed engineering procedure of the new approach is introduced in this study. The applicability of the new approach is verified in comparison to the current industrial approaches via consideration of the safety zone design on a floating LNG-fueled power plant.

\section{Industry Practices for Safety-Zone Layout Design}

The ISO presents the engineering approaches for the design of the LNG safety zone in terms of the risk assessment method. These methods are divided into two approaches, with the selection made according to the target bunkering scenario (ISO, 2015a). The ISO recommends a qualitative approach for standard bunkering scenarios (shore-to-ship, truck-to-ship, and ship-to-ship transfers), and a quantitative approach should be used for other cases.

The main difference between these two approaches lies in their consideration of possible leak scenarios and personnel risk in the safety zone design. The guidelines of the Norwegian classification society (DNVGL), which are based on the ISO guidelines, facilitate easier and more detailed understanding of the safety zone layout design and relevant risk assessment tasks (DNVGL, 2015). The DNVGL guideline introduces the concept of deterministic and risk-based engineering approaches, which are the same as the qualitative and quantitative approaches in the ISO guidelines (ISO, 2015a). Figure 2 shows the flow chart of the two engineering approaches.

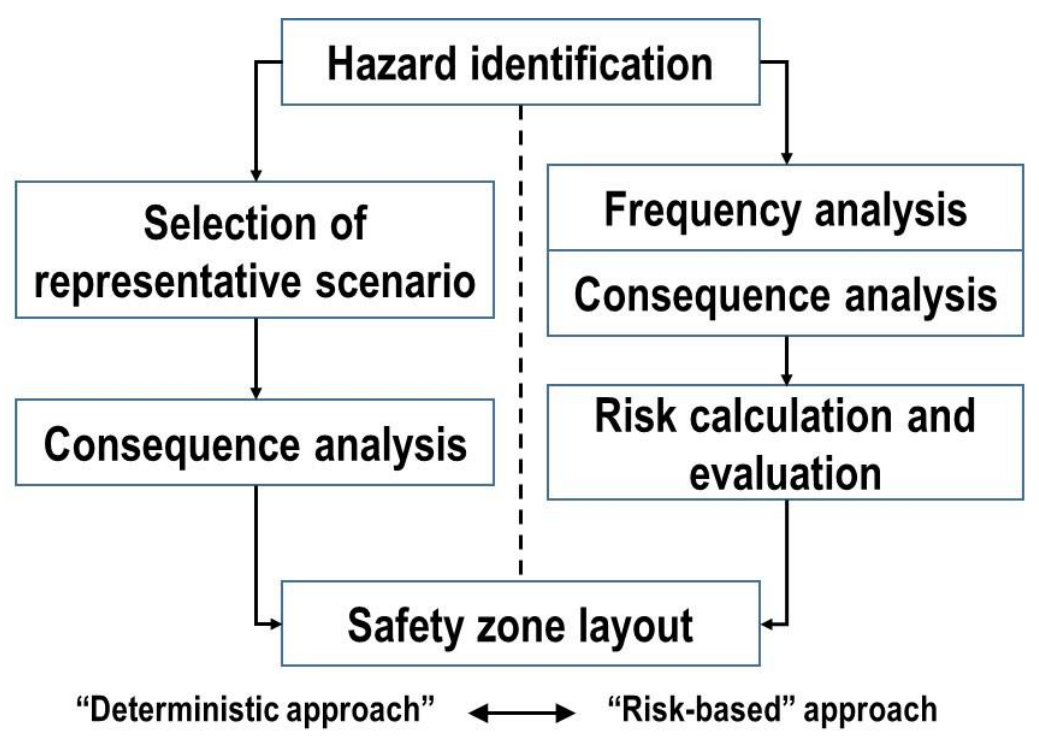

Fig. 2. Flow chart of the deterministic and risk-based engineering approaches. 
In terms of the qualitative or deterministic approach, the LNG facilities under consideration are generally all based on a simple transfer system, such that an LNG leak during bunkering can be considered as a single accidental leak event. The worst or specific conditions of a leak during the bunkering are defined as the representative scenario, and the required safety distance around the facility is then roughly determined, including an expected gas dispersion extent and the flammable limit range of this gas. Currently, most safety zones related to the bunkering operation of the LNG fueled ship are considered with this approach because this structure generally takes its bunkering operation with the standard scenarios and other activities are limited in action.

The quantitative or risk-based approach is applied for other bunkering scenarios that are not included in the standard systems. In this case, all possible accidental leak events relevant to the facility operation are identified and their probabilities of occurrence are estimated. Their consequences are then calculated in terms of various harmful effects, and the safety zone boundary is finally decided in relation to the risk level to personnel. An application of this approach can be considered for the facility with the LNG production system and the simultaneous operation (SIMOPS) of the LNG fueled ship (ISO, 2015a).

Recently, further quantitative approach developments have been made. Jeong et al. (2018), having highlighted the absence of detailed guidelines for the safety exclusion zone of LNG bunkering, introduced an integrated quantitative risk assessment (IQRA) method for this purpose. Park et al. (2018) presented an advanced computational fluid dynamics (CFD) simulation for use in the safety zone design process, incorporating a detailed consequence analysis to be used in association with the quantitative approach. Also, Iannaccone et al. (2019) suggested an integrated safety assessment system for the LNG safety zone based on comprehensive research of the current bunkering systems. Each approach has advantages and disadvantages to its application. The qualitative approach can be applied at the very early design phase to help verify the outline of the overall facility layout. However, this approach tends to calculate an excessively wide safety zone boundary because the leak scenario is conservatively defined with the failure during the bunkering and its consequence is coarsely estimated. In addition, the application of the qualitative approach to complex LNG facilities that do not use standard bunkering systems or have NG or LNG process work should be avoided if possible. One reason for this is that a totally different level of risk can be tolerated during the production operation of an LNG facility with large storage and processing systems rather than 
during its bunkering operation, and therefore the safety zone layout should be designed with a more comprehensive understanding.

In contrast, a relatively less conservative safety zone layout can be designed via a quantitative approach, by use of a probabilistic approach for the scenario selection and an advanced CFD simulation for accurate consequence modelling. However, the detailed risk assessment conducted with this approach requires a large amount of information and therefore becomes practical only once all basic facility design outputs have been determined. The use of this approach may also lead to different safety-zone layouts depending on the engineer responsible for its implementation and his or her computational abilities. In some cases, more conclusive safety distances have been developed with consideration of the transfer system types (CSA, 2018), but most safety zone design of LNG bunkering facilities has been derived from methods similar to the ISO guidelines. Table 2 compares these two industrial engineering approaches.

Table 2. Comparison of two engineering approaches with recommendations on their application.

\begin{tabular}{|l|l|l|}
\hline \multicolumn{1}{|c|}{ Engineering approach } & \multicolumn{1}{|c|}{$\begin{array}{c}\text { Qualitative } \\
\text { (or deterministic) }\end{array}$} & \multicolumn{1}{c|}{$\begin{array}{c}\text { Quantitative } \\
\text { (or risk-based) }\end{array}$} \\
\hline Bunkering scenarios & $\begin{array}{l}\text { Standard scenarios } \\
\text { - Tank to ship (shore to ship) } \\
\text { - Truck to ship } \\
\text { - Ship to ship (offshore supply) }\end{array}$ & $\begin{array}{l}\text { Other systems except for the } \\
\text { standard scenarios }\end{array}$ \\
\hline Considered leak scenario & $\begin{array}{l}\text { Specific (worst) scenario based } \\
\text { on engineering judgement }\end{array}$ & $\begin{array}{l}\text { Credible leak scenarios based on } \\
\text { quantitative risk assessment }\end{array}$ \\
\hline Calculation method & $\begin{array}{l}\text { Analytical solution (simple } \\
\text { computational technique) }\end{array}$ & $\begin{array}{l}\text { Detail computational technique } \\
\text { (3-D CFD simulation) }\end{array}$ \\
\hline $\begin{array}{l}\text { Criteria for safety zone } \\
\text { layout }\end{array}$ & $\begin{array}{l}\text { Flammable limit range based on } \\
\text { expected gas dispersion area }\end{array}$ & $\begin{array}{l}\text { Risk level associated with } \\
\text { various criteria such as } \\
\text { flammable limit, heat radiation, } \\
\text { over-pressure, etc. }\end{array}$ \\
\hline $\begin{array}{l}\text { Design phase } \\
\text { application }\end{array}$ & $\begin{array}{l}\text { Very early stage: } \\
\text { Conceptual design or } \\
\text { Pre-front-end-engineering } \\
\text { design (FEED) }\end{array}$ & $\begin{array}{l}\text { Later stage: } \\
\text { After Pre-FEED or FEED with } \\
\text { prepared process information }\end{array}$ \\
\hline
\end{tabular}

As seen from the above, the ISO and other relevant guidelines have established the industrial standard for design of the LNG safety zone, but their practical applications are mostly limited to the standard bunkering scenarios using the qualitative approach. In complex LNG facilities, such as the 
floating LNG fueled power plant considered in this paper, however the quantitative one is strongly recommended due to the complexity in their systems. This approach may generate a more reasonable boundary for the safety-zone layout design with the more advanced risk-based solution, but the detailed engineering demanded for application of it to develop LNG facilities such as offshore installations requires large investment in engineering costs and time.

The safety zone layout is akin to a district under the jurisdiction of the facility operator, who should be responsible for preventing, monitoring, and managing all personnel safety inside the area. In this respect, it is best to set an exact boundary for the safety zone at an early stage of facility design. Thereafter, it seems that a more intuitive approach is needed to help the design of safety zones for various types of LNG facilities at their earlier stages of the project development.

\section{Hybrid Approach for the Safety-Zone Layout Design of a Floating LNG-Powered Plant}

In this study, a new approach was developed to assess the feasibility of the concept design for a floating LNG-fueled power plant. This approach aims to generate a reasonable safety-zone layout before the front-end-engineering design (FEED) or detailed design phase of the floating power plant and various LNG facilities. The new approach is a hybrid of qualitative and quantitative approaches that combines the advantages of two industrial engineering approaches (DNVGL, 2015; ISO, 2015a): development of the safety zone layout at an early design phase (as done in the qualitative approach) and development of a more reliable safety boundary based on the frequency analysis of possible leak scenarios (as done in the quantitative approach). Figure 3 presents a desirable application process for the hybrid and industrial approaches in association with the development of marine systems (ABS, 2017).

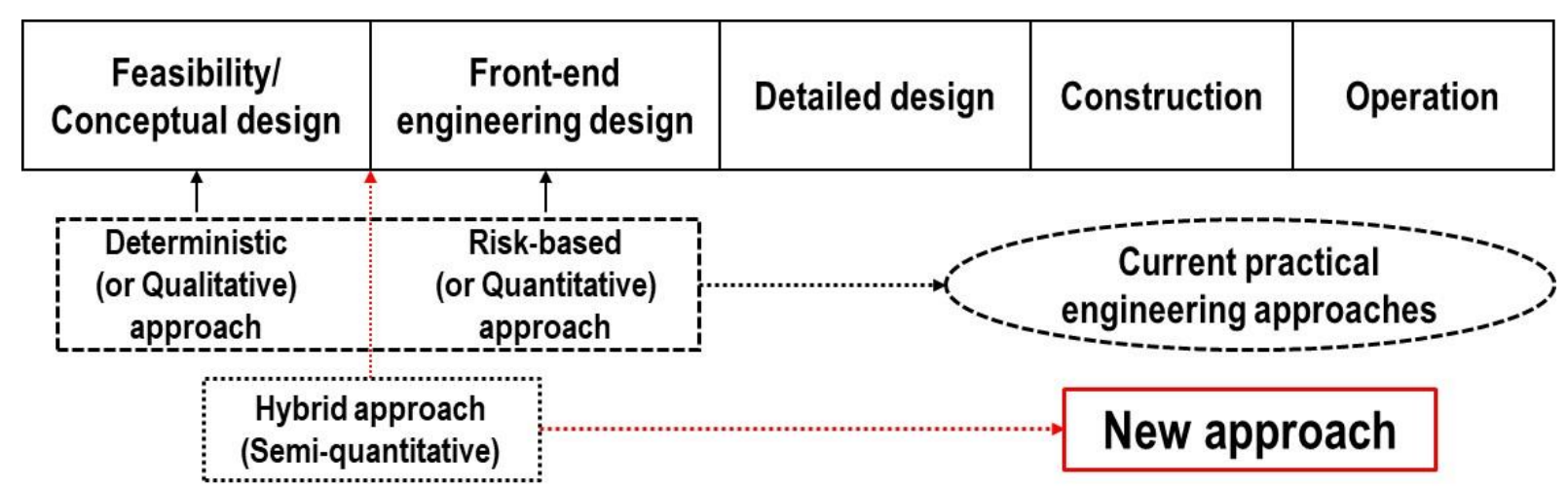


Fig. 3. Comparison between the new and existing (current) industrial engineering approaches in relation to applicability to their design phase

Figure 4 presents the overall procedure of the new, hybrid engineering approach for the safety zone design. During the conceptual design phase, the fundamental engineering work is performed and the inherent safety of the facility design is verified by the HAZID study. As a result, all LNG or NG leak events are identified and their risk rankings are estimated with "risk assessment" phase using simple assessment techniques.

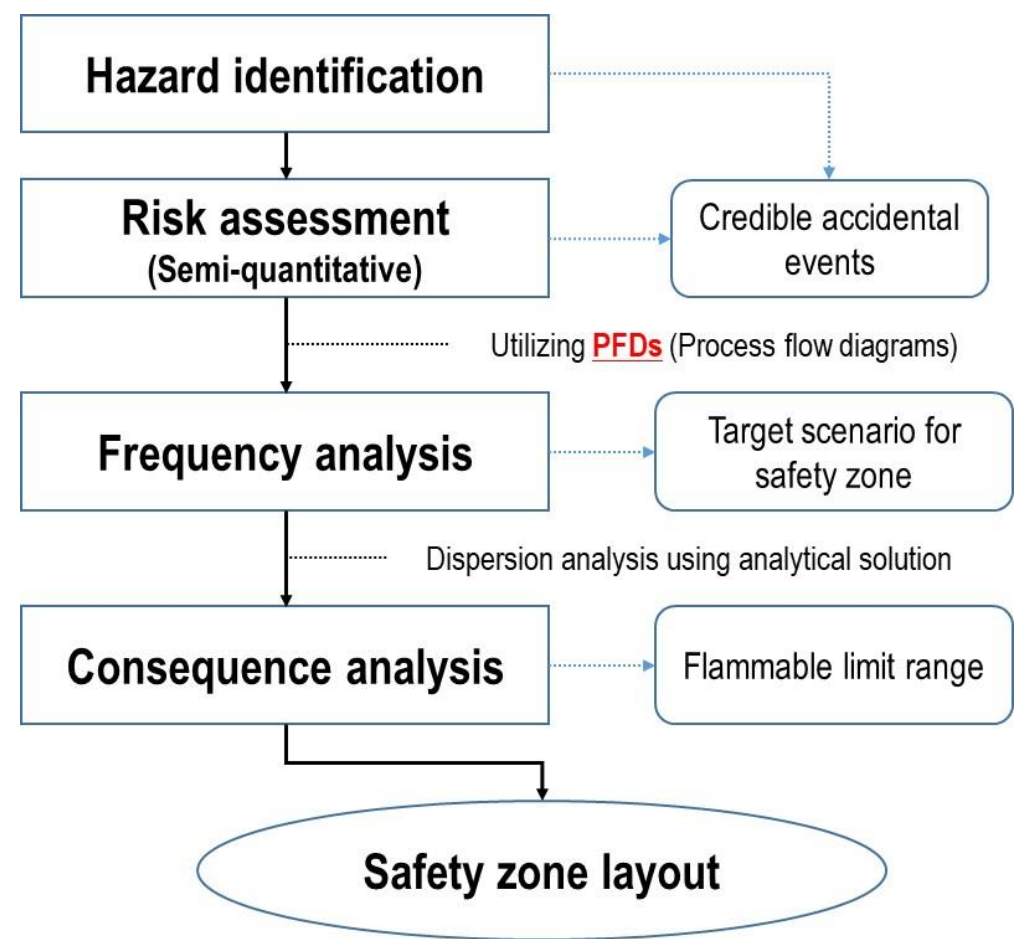

Fig. 4. Procedure of the new approach for the safety zone design of a LNG facility.

After this stage, events are defined as credible leak scenarios based on their risk ranking, and their probable frequency of occurrence is calculated with "frequency analysis" phase utilizing the process flow diagrams (PFDs). The PFDs is a set of general flow diagrams of the facility process and, it is prepared at an early design stage to reveal the expected conditions of all process flows and the interrelationships of major equipment in a facility. The PFDs is developed into the process and instrument diagrams (PIDs) at later design stages with more detailed process information, and the PIDs is normally used in the frequency analysis of the quantitative approach at the FEED or detail design stage of the facility. 
The PFDs enables all process flowlines of a facility to be divided into a set of isolatable sections based on the location of each section's emergency shut-down valve (ESDV). Each isolatable section is considered in the possible leak inventory, and its frequency of leakage is calculated via the parts-count study based on the existing process equipment and pipelines on the PFDs. In relation to this, several organizations provide historical failure data of process item, such as the specific leak frequencies of various pipelines, vessels, and equipment in relation to facility types (DNVGL, 2019b; OGP, 2010; SINTEF, 2015; UK HSE, 2010). Figure 5 presents an example of isolatable sections plotted on the imaginary PFDs drawing consisting of a cargo tank, pipelines and valves.



Fig. 5. Example of isolatable sections with the imaginary PFDs drawing

After the leak frequency of all isolatable sections is calculated, the section with the highest leak frequency can be defined as the specific leak point, and NG or LNG leakage from this inventory is designated as the representative scenario for the safety zone layout design. Dispersion followed by leakage of NG or LNG is then simulated using an analytical solution during "consequence analysis" phase, and the safety zone layout is finally determined with the specific level of the flammable limit range. In this case, the flammable limit range is considered as the potential area for the fire with any ignition sources and the person in this area can be exposed to the fatal situation. If a more conservative design is needed, the representative scenario can be selected by also considering leaks from other isolatable sections that are not ranked as having the highest leak frequency. In this case, a responsible engineer may use his or her judgement to consider the importance of each isolatable section, that is, the volume of gas in the section, its flammability, or other characteristics of the flow, before making a design decision. When the flammable limit range is identified, then this area 
can be directly designed as the safety zone and owner or operator of the facility may designate their responsible area around the facility to manage all activities and personal access into the area.

It should be noted that the new approach assumes the leak frequency to be the frequency of the event occurrence considering the gas leak and dispersion followed by, whereas the event frequency of the process accident is originally estimated as the product of the leak frequency and the ignition probability considering fire and explosion after the flammable dispersion in the general risk assessment methodology. The new approach assumes that just a flammable leak has the same effect with fire or explosion without any ignition probability and this may give more conservative results in view of the safety zone area comparing to the qualitative approach. Also, the newly developed hybrid approach defines the safety zone layout regardless of the risk level, whereas the personnel risk level is the main decision factor for the design of the safety zone and other safety systems in the quantitative approach (Jeong et al., 2018). The personnel risk level is generally expressed as the individual risk (IR) and it means the risk experienced by a single individual in a given time period. The IR can be calculated in various ways but normally it takes consideration of the event frequency, consequence and time of existence at the specific location of personnel (CMPT, 1999). Detailed information on the general risk assessment method mentioned in this study can be obtained from various publications (CMPT, 1999; DNVGL, 2017; IMO, 2015; ISO, 2015b, Vinnem, 2014).

In summary, the hybrid approach determines the target scenarios for the design of the safety zone layout with the frequency-based calculated event probability imitating the qualitative approach and defines the safety zone boundary with the flammable limit range like as the quantitative approach. The next chapter shows how the hybrid approach is applied on the practical engineering through the safety zone layout design of a floating LNG fueled power plant.

\section{Applied Example}

The safety-zone layout design of a floating LNG-fueled power plant is considered as the applied example in this study. As the result of the previous HAZID study (Park et al., 2019), the possibility of flammable leak events during bunkering and normal operations of the facility were identified and those are analyzed in detail for the safety zone design. To define the layout boundary of the plant at the early design stage, the qualitative and hybrid approaches are applied, and the dimension of their safety-zone layout boundary are compared. The quantitative approach may derive the most reasonable safety zone layout of the floating power plant but the required information for its 
application is not fully prepared at the early design stage and thus this is excluded from this paper. Nevertheless, it might be necessary to consider the detail engineering approach to make the justification on the application of the hybrid approach in the future work.

The DNVGL Phast program is used to obtain the analytical solution for the gas dispersion simulation of the selected NG or LNG leak scenarios. This is one of the most comprehensive types of software for the process safety management in all stages of design and operation (DNVGL, 2019a), and it provides a very simple but relatively accurate calculation for gas dispersion, types of fires, and explosion phenomena. It is expected that many engineers are familiar with this software and thus an introduction on detail theory or instructions for the usage are out of scope for this paper.

\subsection{Target Design}

The floating LNG-fueled power plant consists of two main parts - a hull and a topside, like other general floating structures - and generates approximately 10 to $20 \mathrm{MW}$ of electrical power via its cargo hold, handling, and processing systems (Fig. 6). Table 3 and Figure 7 depict the principal dimensions and the general arrangement of the plant design.

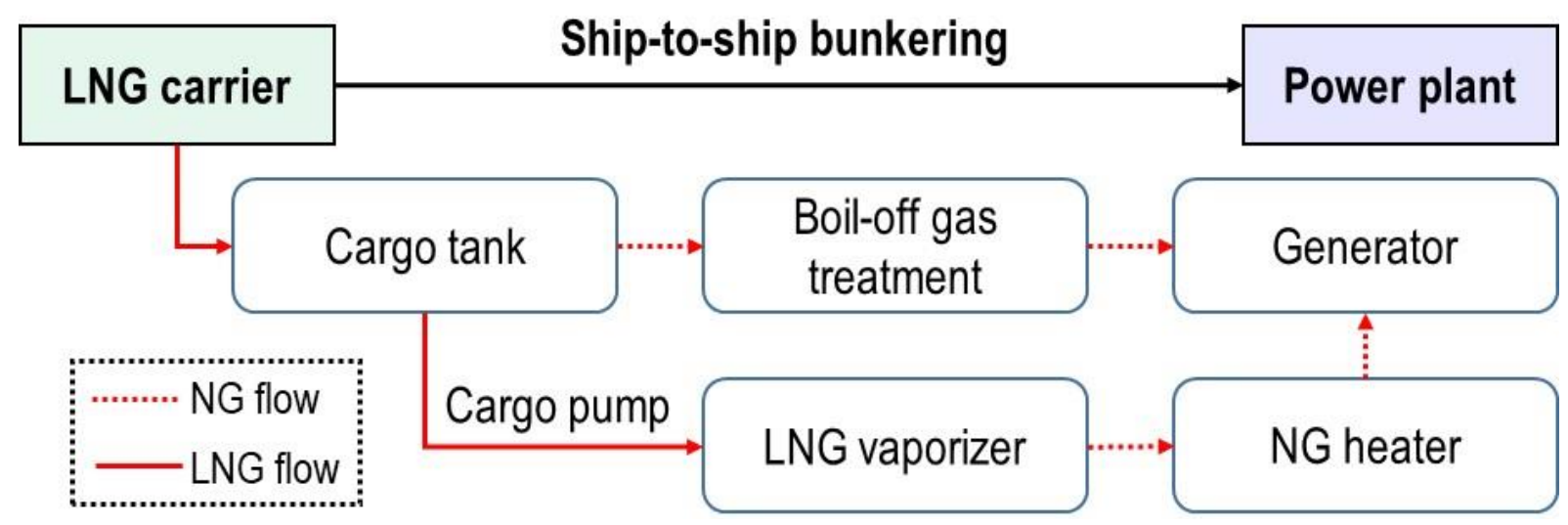

Fig. 6. Conceptual process flow of the floating type LNG power plant.

Table 3. Principal dimensions of the floating power plant hull structure.

\begin{tabular}{|c|c|}
\hline Length Overall (L.O.A.) & approx. $70.0 \mathrm{~m}$ \\
\hline Breadth (molded) & approx. $30.0 \mathrm{~m}$ \\
\hline Depth to upper deck (molded) & approx. $9.0 \mathrm{~m}$ \\
\hline Design draught (molded) & approx. $3.5 \mathrm{~m}$ \\
\hline
\end{tabular}




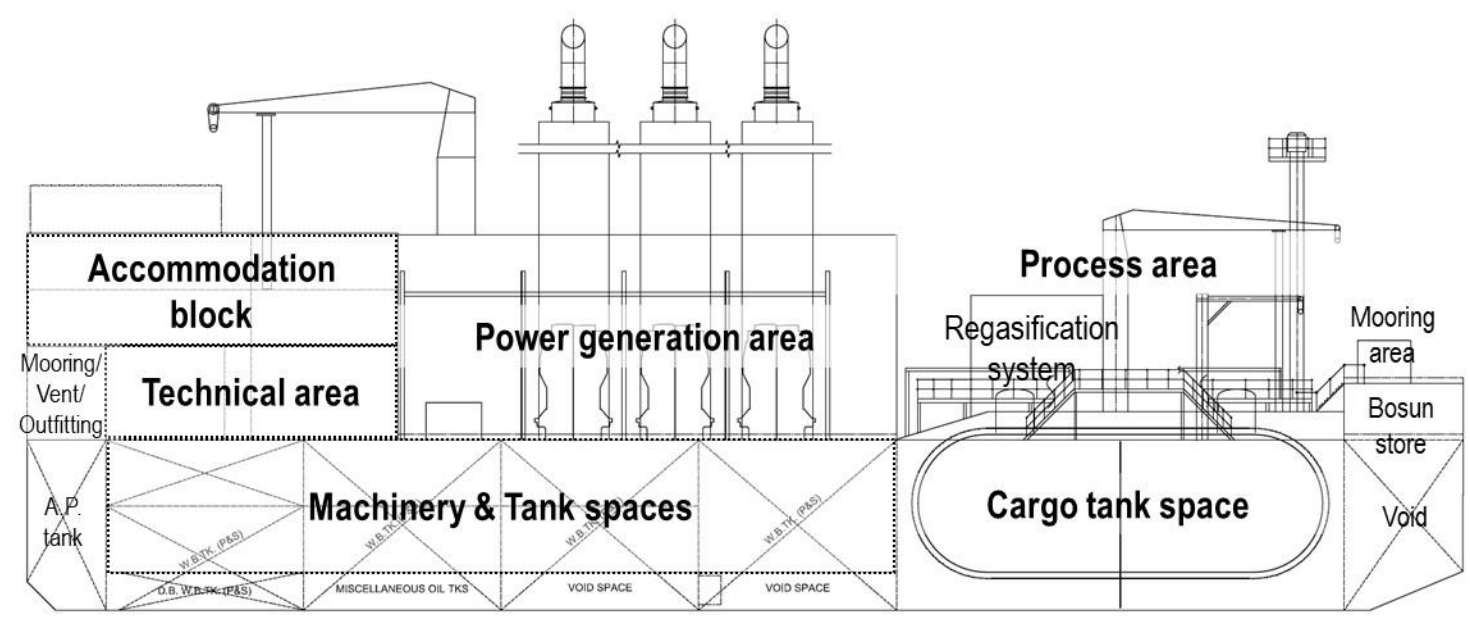

Fig. 7. General arrangement of a floating LNG power plant.

\subsection{Industry Practice - Qualitative or Deterministic Approach}

Based on the previous HAZID study (Park et al., 2019) various leak events during the power plant operation might be defined as the specific scenario with the deterministic approach but this is not the original intention of the qualitative approach. Therefore, only the leakage during the bunkering is considered for the safety zone design of the qualitative approach and a rupture of the flexible hose line is taken as the representative scenario for the gas dispersion simulation. The rupture case is deliberately chosen to result a wide boundary of the safety zone and this will help the facility owner or operator to verify the responsible area at the early design stage providing enough margin in the design.

The LNG transfer between a small-scale LNG carrier (LNGC) and the power plant is accomplished with a ship-to-ship bunkering system, and the expected transfer rate is $666 \mathrm{~m}^{3} / \mathrm{h}$. At this rate, the maximum cargo tank capacity of $2000 \mathrm{~m}^{3}$ is reached in 3 hours. With reference to the location of the ESDV on the flexible line, the total volume of possible LNG leakage is estimated by summation of the dynamic and static flows. The dynamic flow is the transfer rate stipulated in the design, and the static flow is the isolated volume remaining after the emergency shut-down process. The activation time of the ESDV is assumed to be $30 \mathrm{~s}$, and then the total volume for leakage is estimated as $2700 \mathrm{~kg}$. This entire volume is expected to be open for release during an accident event until the pressure levels between internal and outer of the flowline become equilibrated.

It is noteworthy that the safety zone of the LNG facility with the standard bunkering is defined with the qualitative approach following the current industrial guidance. Normally, it is accepted as the way of the engineering practice, but sometimes it raises question about the reliability of that way because the resulted safety zone boundary depends on the only single leak scenario. This approach may derive the huge difference on the safety zone boundary based on the defined scenario in association with its flammable leakage volume, leak position, leak size \& release rate, etc. 
Therefore, the selection of the appropriate scenario is a very important factor of the qualitative approach and the argument may always exist on this issue.

\subsection{Proposed - Hybrid Approach}

In case of the hybrid approach, the safety zone design takes into account all possible leak events during the plant operation. The process pipelines are divided into several isolatable sections based on the location of ESDVs on the PFDs, and these are listed separately for the bunkering and normal operations. The plants's heat and material balance (H\&MB) sheet is used to identify the detailed flow information to enable the total amount of possible leakage from each isolatable section to be calculated. Although a process flow in an isolatable section may differ from the designed operating condition due to the simultaneous bunkering and production operations, the possible leak volume of all isolatable sections is calculated with the dynamic and static flows considering their normal design condition. Tables 4 and 5 list the defined isolatable sections for the bunkering and normal operations, and several isolatable sections marked up on the PFDs can be found in Fig. 8. The large amount of LNG in the cargo tank is assumed with the approximate estimation of the tank volume and exactly same values are given for the isolatable sections on the cargo tank during bunkering and the normal operations (No. 3 of Table 4 and No. 1 of Table 5).

Table 4. Isolatable sections for the bunkering operation of the floating LNG-fueled power plant.

\begin{tabular}{|c|c|c|c|c|}
\hline No & Node ID & Description & Note & Volume (kg) \\
\hline 1 & In-01 & $\mathrm{LNGC} \sim \mathrm{ESDV}$ & \multirow{4}{*}{$\begin{array}{l}\text { Inflow } \\
\text { (LNG) }\end{array}$} & 2696.8878 \\
\hline \multirow{3}{*}{2} & In-02 & ESDV Break point & & 2652.2229 \\
\hline & In-02B & Break point $\sim$ ESDV & & 1378.2204 \\
\hline & In- $02 C$ & Break point $\sim$ ESDV & & 1378.2204 \\
\hline \multirow{2}{*}{3} & S-01A & Cargo tank (A) & \multirow{2}{*}{$\begin{array}{c}\text { Storage } \\
\text { (LNG) }\end{array}$} & 459100 \\
\hline & S-01B & Cargo tank (B) & & 459100 \\
\hline \multirow{3}{*}{4} & Out-01A & ESDV $\sim$ Crossing point & \multirow{6}{*}{$\begin{array}{l}\text { Outflow } \\
\text { (NG) }\end{array}$} & 0.3658 \\
\hline & Out-01B & ESDV $\sim$ Crossing point & & 0.3658 \\
\hline & Out-01C & Crossing point $\sim$ SDV & & 0.1829 \\
\hline 5 & Out-02 & $\mathrm{ESDV} \sim \mathrm{LNGC}$ & & 0.1829 \\
\hline \multirow{2}{*}{6} & Out-04A & Cargo tank $(\mathrm{A}) \sim$ Vent & & 0.0057 \\
\hline & Out-04B & Cargo tank $(\mathrm{B}) \sim$ Vent & & 0.0057 \\
\hline
\end{tabular}


Table 5. Isolatable sections for the normal operation of the floating LNG-fueled power plant.

\begin{tabular}{|c|c|c|c|c|}
\hline No & Node ID & Description & Note & Volume $(\mathrm{kg})$ \\
\hline \multirow{2}{*}{1} & $\mathrm{~T}-01 \mathrm{~A}$ & Cargo tank (A) & \multirow{2}{*}{$\begin{array}{l}\text { Storage } \\
\text { (LNG) }\end{array}$} & 459100 \\
\hline & $\mathrm{T}-01 \mathrm{~B}$ & Cargo tank (B) & & 459100 \\
\hline \multirow{2}{*}{2} & L-01A & Pump ESDV & \multirow{5}{*}{$\begin{array}{l}\text { Liquid line } \\
\text { (LNG) }\end{array}$} & 28.9216 \\
\hline & L-01B & Pump $\sim$ ESDV & & 28.9216 \\
\hline \multirow{2}{*}{3} & $\mathrm{~L}-02 \mathrm{~A}$ & ESDV $\sim$ Crossing point & & 24.2690 \\
\hline & L-02B & Crossing point $\sim$ ESDV & & 43.8855 \\
\hline 4 & L-03 & ESDV Vaporizer & & 43.8855 \\
\hline \multirow{2}{*}{5} & L-04A & Heater & \multirow{2}{*}{$\begin{array}{l}\text { Liquid line } \\
\text { (NG) }\end{array}$} & 39.2609 \\
\hline & L-04B & Heater $\sim$ ESDV & & 39.2826 \\
\hline 6 & L-05 & $\mathrm{ESDV} \sim \mathrm{ESDV}$ & $\begin{array}{l}\text { Liquid line } \\
\text { (LNG) }\end{array}$ & 30.5392 \\
\hline \multirow{3}{*}{7} & G-01A & ESDV $\sim$ Crossing point & \multirow{8}{*}{$\begin{array}{c}\text { Gas line } \\
\text { (NG) }\end{array}$} & 1.8002 \\
\hline & G-01B & ESDV $\sim$ Crossing point & & 1.8002 \\
\hline & G-01C & Crossing point $\sim$ ESDV & & 3.3809 \\
\hline \multirow{3}{*}{8} & G-02A & $\mathrm{ESDV} \sim \mathrm{BOG}$ tank & & 2.8745 \\
\hline & G-02B & BOG Compressor & & 0.2820 \\
\hline & G-02C & BOG Compressor & & 2.8802 \\
\hline \multirow{2}{*}{9} & G-03A & Heater & & 2.8802 \\
\hline & G-03B & Heater $\sim$ SDV & & 2.8745 \\
\hline 10 & A-01A & ESDV $\sim$ Crossing point & $\begin{array}{l}\text { Merged line } \\
\text { (NG) }\end{array}$ & 39.2577 \\
\hline
\end{tabular}






Fig. 8. Illustrative example of the isolatable sections marked on the PFDs of the floating power plant

All process-relevant items in isolatable sections are verified via the parts-count study, and their frequency of leaks are calculated using historical data (OGP, 2010). The PFDs does not provide detailed information on pipeline length, and thus the total leak volume and the leak frequency of pipelines in each isolatable section are approximated. It needs to be noted that the OGP data used for this study is not the latest one and not exactly suitable for the LNG system and thus the engineer may utilize other resource in his or her responsibility for their study.

It is important to note that the failure data for loading arms and flexible hoses that are used for the LNG transfer between the LNGC and the power plant should be considered in a different manner than the general process-relevant items in the oil and gas industry. However, the statistics on the historical failure data of the LNG systems are not established yet and only limited resources are accessible (SGMF, 2018). Also some research output have assumed a very low release frequency for this transfer equipment and therefore considered leakage during the bunkering as a minor risk (Fluxys, 2012; UK HSE, 1991; UK HSE, 2019). Accordingly, the leak-frequencies of these transfer systems are calculated in the same way as those of the general process items of the oil \& gas industry in this study. Tables 6 and 7 indicate the calculated leak frequencies of all isolatable sections that are relevant to the bunkering and normal operations. 
Table 6. Leak frequency for all isolatable sections during the bunkering.

\begin{tabular}{|c|c|c|c|c|c|}
\hline No & Node ID & Pipe diameter $(\mathrm{m})$ & Amount $(\mathrm{kg})$ & $\begin{array}{c}\text { Frequency } \\
\text { (/year) }\end{array}$ & Ranking \\
\hline 1 & In-01 & 0.2032 & 2696.88 & 0.000076 & 5 \\
\hline 2 & In-02 & 0.2032 & 5408.66 & 0.002890 & 3 \\
\hline 3 & S-01 & - & 918200 & 0 & 6 \\
\hline 4 & Out-01 & 0.2032 & 0.91 & 0.004935 & 1 \\
\hline 5 & Out-02 & 0.0508 & 0.18 & 0.001175 & 4 \\
\hline 6 & Out-04 & 0.0508 & 0.01 & 0.004510 & 2 \\
\hline
\end{tabular}

Table 7. Leak frequency for all isolatable sections during normal operation.

\begin{tabular}{|c|c|c|c|c|c|}
\hline No & Node ID & Pipe diameter $(\mathrm{m})$ & Amount $(\mathrm{kg})$ & $\begin{array}{c}\text { Frequency } \\
\text { (/year) }\end{array}$ & Ranking \\
\hline 1 & T-01 & - & 918200 & 0 & 10 \\
\hline 2 & L-01 & 0.0508 & 57.84 & 0.005740 & 7 \\
\hline 3 & L-02 & 0.0508 & 68.15 & 0.004194 & 8 \\
\hline 4 & L-03 & 0.0508 & 43.88 & 0.005607 & 6 \\
\hline 5 & L-04 & 0.1016 & 78.54 & 0.006987 & 4 \\
\hline 6 & L-05 & 0.0508 & 30.54 & 0.006553 & 5 \\
\hline 7 & G-01 & 0.2032 & 6.98 & 0.007358 & 3 \\
\hline 8 & G-02 & 0.0508 & 6.04 & 0.019032 & 1 \\
\hline 9 & G-03 & 0.0508 & 5.75 & 0.007374 & 2 \\
\hline 10 & A-01 & 0.1016 & 84.33 & 0.004700 & 9 \\
\hline
\end{tabular}

The results of the leak frequency calculation show that the possibility of leakage during normal operation is much higher than during the power plant's bunkering operation. The leakage from the No. 8 isolatable section (Table 7) is ranked as the highest frequency event, and an accidental line rupture in this section is defined as the representative scenario for the safety zone design in the hybrid approach. As mentioned in the section 4.2, although the rupture of the pipeline is very rare and somewhat unrealistic event, this is applied for the gas dispersion simulation for the conservative result on the safety zone layout. It is worthwhile to note that the leakage from the cargo tank may cause the catastrophic accident but any leakage from the power plant's cargo tank is considered as the incredible event and thus ignored in this study. 


\subsection{Design Results and Discussion}

Based on selected scenarios in the industrial - qualitative approach and the hybrid approach, various parameters are entered into the DNVGL Phast program, and the boundary of the lower flammable limit range is derived from the gas dispersion simulation. Identical input values for the environmental conditions, such as ambient temperature, humidity, wind speed, and direction, were used in both approaches. The red dot in Fig. 9 shows the imaginary location of the power plant operation captured the google map application, and the simulation results are presented on this map to indicate the approximate scale of the safety-zone boundary.

In qualitative and hybrid approaches, the safety zone is expressed as a radius around the plant location based on the maximum lower flammable limit (LFL) distance resulted in the specific direction of leak and dispersion. Therefore, the leak direction is a meaningless factor in those approaches but it can play an important role in the quantitative approach. This approach defines the credible leak events and their likelihood in detail and the probability of possible leak directions are reflected in the estimation of the event frequency. In regard to this, possible leak directions are determined on the basis of the surrounding condition around the leak point and several leak events can be derived from the specific leak point in regard to its leak directions. To summarize, a leak point on an isolatable section is developed into the target scenario of qualitative and hybrid approaches and it results the safety zone boundary as the radius around the plant regardless of the leak direction. However, a leak point can take several leak directions with different probability and it will cause the asymmetry shape of the safety zone boundary in association with the personnel inhabitancy in the quantitative approach. More detail information on the relationship between the event frequency and the leak direction can be found in the research paper proposed by Paik (2019). 


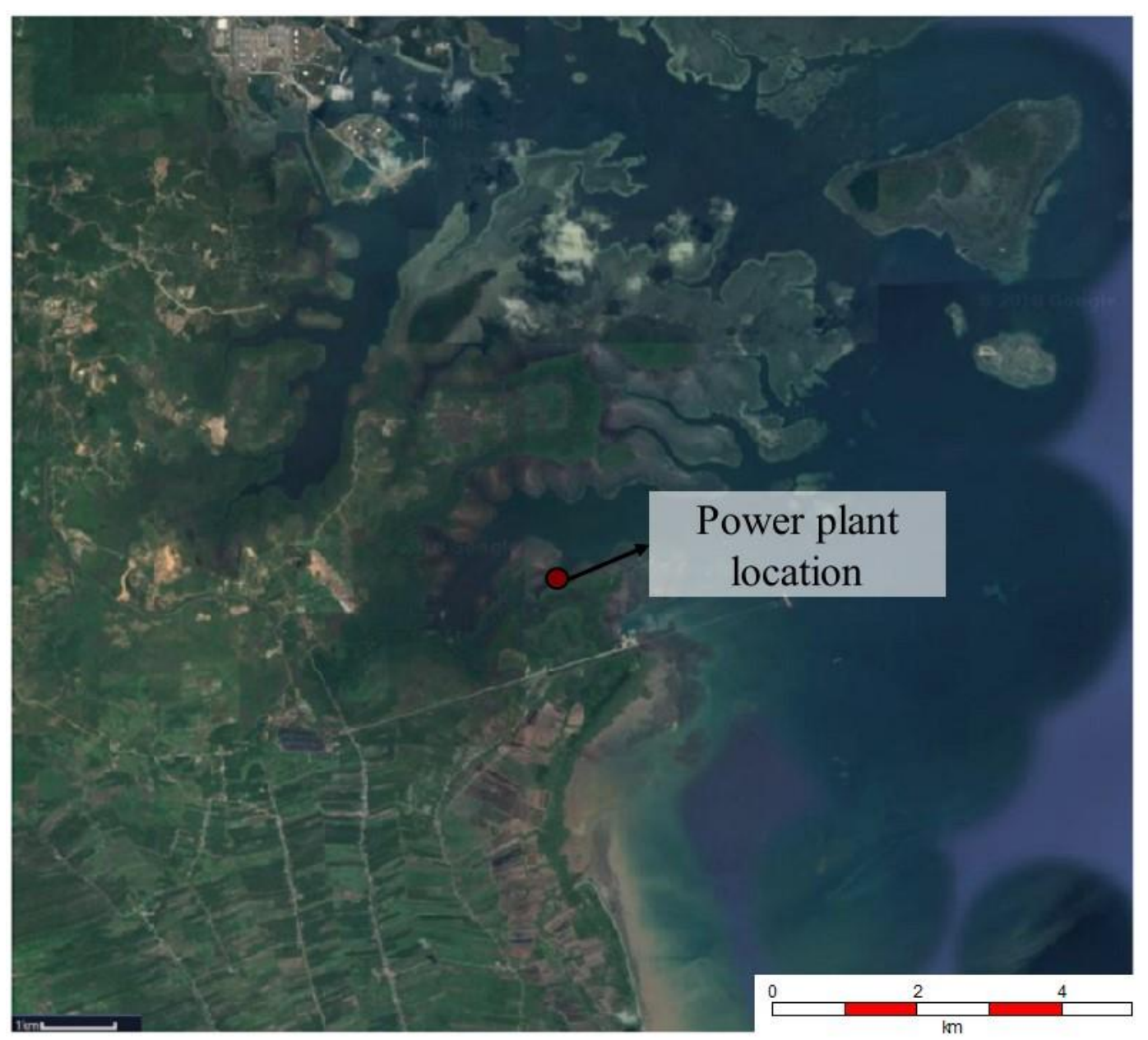

Fig. 9. Illustrative example for an expected location of the floating LNG-fueled power plant.

Figure 10 presents the results of the gas dispersion simulation and derived safety zone layouts from the qualitative approach. The green and red circles denote the LFL range and half of the LFL range around the plant, which can be designated as the safety zone and additional control (security) zone boundary of the floating LNG-fueled power plant. Based on the selected scenario, the rupture of the LNG loading line, the LFL and a half of the LFL distances of $106 \mathrm{~m}$ and $190 \mathrm{~m}$ are observed along the leak direction and those values are applied as the radius of circles. 




Fig. 10. Illustrative example for the safety and control zone boundaries resulting from the qualitative approach (No. 1 isolatable section in Table 6).

Figure 11 presents the results of the safety zone layouts from the hybrid approach. It can be seen that much smaller boundary than the qualitative approach is made and even it does not draw any LFL range around the facility. Based on the frequency calculation, a relatively small leak amount was considered as the representative scenario of the hybrid approach and this derived about $20 \mathrm{~m}$ of the security zone around the power plant. This may not be a meaningful boundary for the safety zone layout because the safety zone is required to be larger than the hazardous area in the facility as minimum (SGMF, 2018). It is therefore decided that a more conservative safety zone design would be needed for the floating power plant with the hybrid approach.

The LNG and NG leaks from No. 5 and 10 isolatable sections in Table 7 are then selected as additional scenarios to cover both possible leak amounts and frequencies. Figures 12 and 13 present the safety zone boundaries resulted from these additional scenarios and they provide clear safety and security zones around the facility which is not denoted in the original scenario of the hybrid approach. 


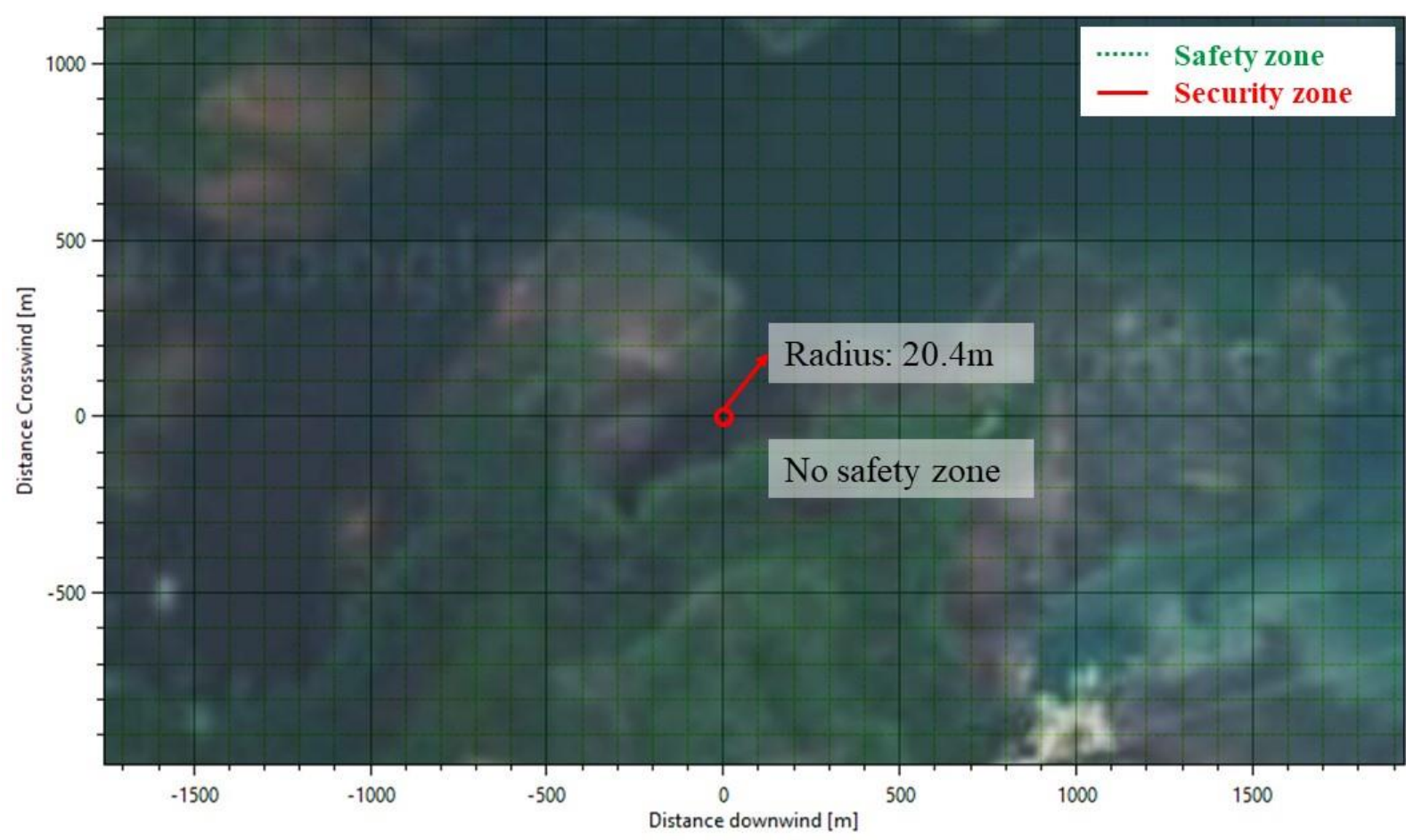

Fig. 11. Illustrative example for the safety and control zone boundaries resulting from the new approach (No. 8 isolatable section in Table 7).

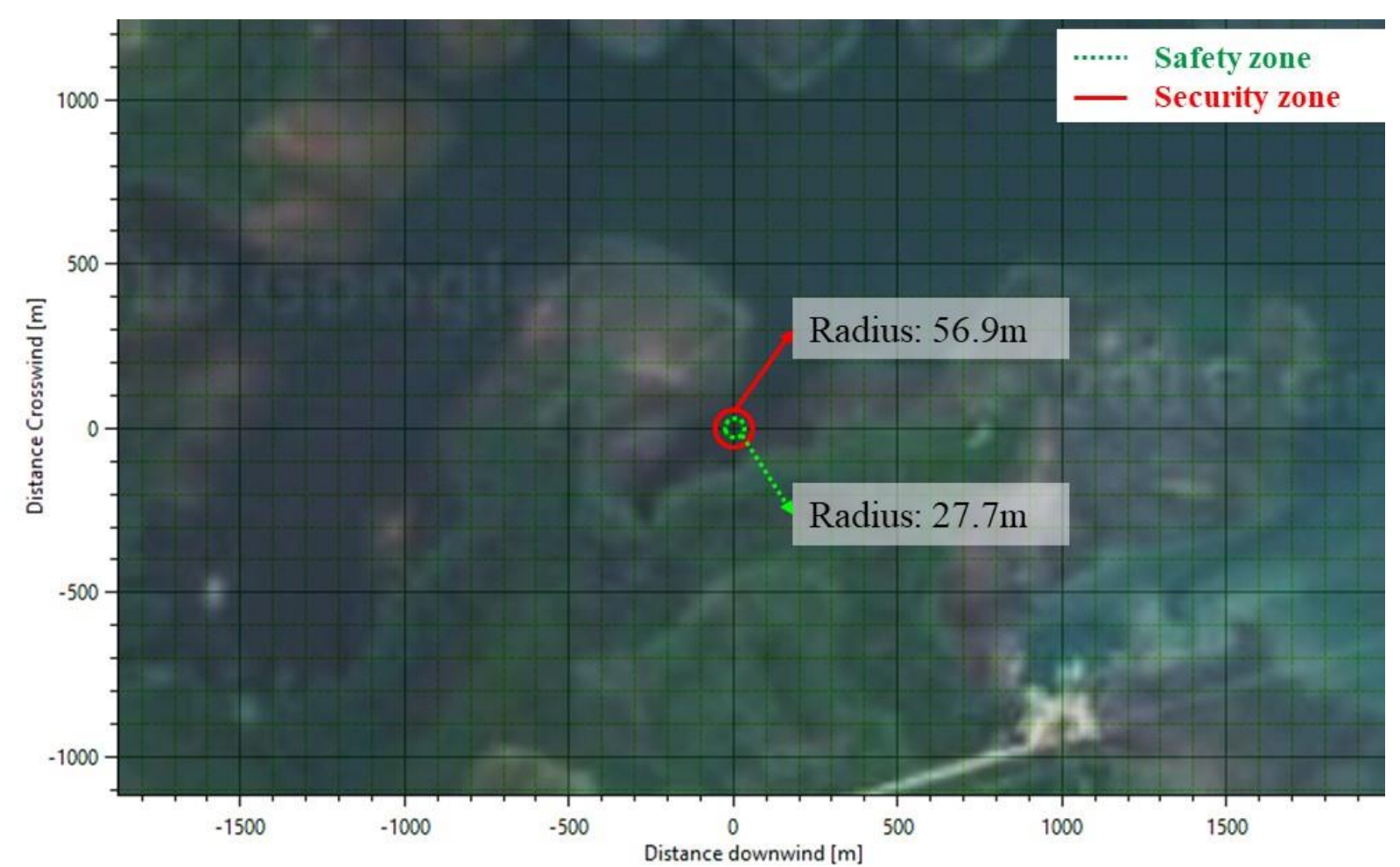

Fig. 12. Illustrative example for the safety and control zone boundaries generated by the new approach (No. 5 isolatable section in Table 7). 




Fig 13. Illustrative example for the safety and control zone boundaries resulting from the new approach (No. 10 isolatable section in Table 7).

Table 8 provides the summary of all simulated scenarios for the safety- and control-zone boundaries of the floating LNG-fueled power plant. It shows a large difference between the safety zone boundaries generated by the qualitative and hybrid approaches. Although two additional scenarios generate larger boundaries than the representative scenario of the hybrid approach, these are much smaller than those generated by the qualitative approach. This difference may be derived from the frequency analysis in the hybrid approach, that is, the probabilistic consideration of the leak event.

The data in Tables 6 and 7 indicate that a leak is unlikely to occur during bunkering, and the worst scenario of the qualitative approach has an extremely low predicted frequency value in comparison to the predicted frequency of a possible leak during normal operation. The process lines that transport a large amount of flammable fluid or flammable fluid in a high pressure condition are designed with the special care. Generally these are fully welded and then less connection points are made along the pipelines so far as possible to prevent any accidental leaks. Also, the greatest care is taken in their operation, especially in the bunkering. In this regard, it is acceptable to assume that an accidental leak during the LNG bunkering can be effectively prevented and controlled with reliable equipment and well-established working procedures. The historical failure data of various process facilities may support this opinion (Fluxys, 2012; UK HSE, 1991; UK HSE, 2019). 
Interestingly, the frequency calculation in the hybrid approach shows that an isolatable section with higher leak frequency (low ranking) takes larger amount of the leakage volume. It means that a leak from an isolatable section with lower ranking would make more wider safety zone boundaries but further scenarios are not considered in this study. Finally, the hybrid approach of this study enables the safety zone of the floating LNG-fueled power plant to be designed with maximum and minimum distances from the plant location of approximately $57 \mathrm{~m}$ and $21 \mathrm{~m}$, respectively. These distances will be finalized in the project decision-making process.

Table 8. Safety and control zone boundaries (radius) for the floating type LNG power plant.

\begin{tabular}{|c|c|c|c|}
\hline Approach & Scenario & Safety zone $(\mathrm{m})$ & Control zone $(\mathrm{m})$ \\
\hline Qualitative & Worst case & 106.7 & 190.6 \\
\hline Hybrid & No. 5 in Table 7 & 27.7 & 56.9 \\
\hline Hybrid & No. 10 in Table 7 & 18.7 & 49.1 \\
\hline Hybrid & Representative & - & 20.4 \\
\hline
\end{tabular}

Based on the result in the chapter 4, the benefit of the hybrid approach can be summarized in comparison with current industrial approaches as below:

- The hybrid approach derives the design of the safety zone layout at the earlier design stage of LNG facilities comparing to the quantitative approach. The safety zone design was set at the conceptual design stage of the power plant when the enough information is not prepared to apply the quantitative approach. Although it still requires more design information than the qualitative approach, it may provide the practical solution for a complex LNG facility with the minimum engineering costs and time.

- The hybrid approach provides a more reasonable safety zone boundary in comparison with the qualitative approach. The hybrid approach takes account of event probabilities of NG or LNG leakage similar as the quantitative approach and this may lead to less conservative or realistic safety zone boundaries of a LNG facility in the view of the risk-based design.

- The hybrid approach utilizes a simple calculation method for the safety zone boundary in association with the gas dispersion area utilizing an analytical solution like as the qualitative approach. This may increase the consistency on the safety zone layout result regardless of engineering experience and proficiency in the computational skill of the engineer.

- The hybrid approach defines an intuitive layout of the safety zone providing the radius of a circle around a LNG facility. This approach determines the safety zone boundary regardless of the leak direction and the risk level which will be different in the locations of personnel. This may help the project manager understand their responsible area for the facility operation.

It should be noted again that the hybrid approach considers only the leak frequency in terms of its risk-ranking and the scenario selection. However, by means of the general risk assessment, the risk 
level is quantitatively estimated as a multiplication of event frequency and consequence or a combination of event frequency, consequence and personnel inhabitancy around the facility. The key point of the hybrid approach is to define the risk with only event frequencies and it enables to derive the reasonable safety zone from the simple consequence calculation. However, due to the unpredictable consequences of flammable leakage including not only the gas dispersion but various fire and explosion types, it may instead require a detail consequence analysis with the quantitative approach.

In addition, the hybrid approach operates on several assumptions during the frequency analysis in association with the usage of the PFDs. Some uncertainties exist within the PFDs regarding the process systems, and these could be ameliorated by the development of PIDs at the later stage. In this context, the calculated frequency of possible leak events from the quantitative approach may differ from the hybrid approach.

\section{Concluding Remarks and Future Work}

This study proposes an approach for the safety-zone layout design of LNG facilities and presents its application to the development of a floating LNG-fueled power plant. Based on the results of this study, the following conclusions can be made.

(1) The proposed approach is developed as the practical solution for the safety zone layout design of a complex LNG facility such as the floating LNG power plant.

(2) The proposed approach is a hybrid method that combines the characteristics of current industry practices. This approach defines the safety-zone layout at the early stage of the facility design (like the qualitative approach) and considers the possibility of a leak event in designing a reasonable layout boundary (like the quantitative approach).

(3) The hybrid approach uses process flow diagrams (PFDs) for its leak-frequency analysis and regards the leak frequency as the event frequency. Based on this probabilistic consideration, this approach can provide a relatively realistic safety zone boundary compared to that obtained from the qualitative approach. The frequency analysis of the applied example in this study showed that the leak scenario used in the qualitative approach could bring a too conservative result.

(4) The hybrid approach can be used flexibly by the engineer with overall responsibility with the use of his or her engineering judgement. In principle, the representative scenario selected should be that with the highest leak frequency, but leakage from specific isolatable sections can also be considered based on flow characteristics, which may lead to the design of a more reasonable safety zone boundary. 
(5) The hybrid approach uses an analytical method to derive a solution for its consequence analysis of the selected leak scenario like as the qualitative approach while the quantitative approach prefer to 3D CFD. Here, the analytical method used was provided by the DNVGL Phast software. Various other commercial programs have been widely used for practical engineering purposes, and these generally provide a conservative result for the gas dispersion and other accidental process phenomena, via simple calculation.

(6) The applied example confirms that the hybrid approach provides much smaller safety zone boundaries for a floating LNG-fueled power plant than the qualitative approach does. Moreover, even if additional leak scenarios are considered in the hybrid approach to yield conservative results (i.e., larger safety zone boundaries), these boundaries are still smaller than those generated with the qualitative approach.

(7) The qualitative approach provides a direct and simple design method on the safety zone layout but it is difficult to discuss on the reliability of its result due to its deterministic scenario. Although the LNG society has tried to suggest any recommendations on the selection of the credible scenario in this approach (SGMF, 2018), more and much detail research data seem to be needed for its unconstrained application.

The benefits of the proposed approach are that a reasonable safety-zone layout of the LNG facility can be determined as early as possible in the design process. However, although the resulting safety design of the floating LNG-fueled power plant may support the applicability of the hybrid approach, some uncertainties remain regarding its general applicability to such an LNG facility in comparison to use of the qualitative approach. Future work should thus involve a comparison between the hybrid and qualitative approaches to enable a justification to be made for the use of the hybrid approach in the practical engineering of safety zone layout design for floating LNG-fueled power plants.

\section{Acknowledgements}

The present work was undertaken at the Korea Ship and Offshore Research Institute of Pusan National University which has been a Lloyd's Register Foundation Research Centre of Excellence since 2008. This work was supported by a 2-Year Research Grant of Pusan National University.

\section{References}

ABS, 2017. Guidance notes on review and approval of novel concepts. American Bureau of Shipping, Houston, TX, USA.

CMPT, 1999. A guide to quantitative risk assessment for offshore installations. The Centre for 
Marine and Petroleum Technology, Bristol, UK.

CSA, 2018. Liquefied natural gas (LNG) - production, storage, and handling. Canadian Standards Association, Ontario, Canada.

DNVGL, 2015. Recommended practice A105: development and operation of liquefied natural gas bunkering facilities. Det Norske Veritas Group, Oslo, Norway.

DNVGL, 2017. Recommended practice A203: technology qualification. Det Norske Veritas Group, Oslo, Norway.

DNVGL, 2019a. Process hazard analysis software (Phast). Det Norske Veritas Group, Oslo, Norway.

DNVGL, 2019b. World offshore accident database. Det Norske Veritas Group, Oslo, Norway.

Fluxys, 2012. Safety study - chain analysis: supplying Flemish ports with LNG as marine fuel. Fluxys, Brussels, Belgium.

Iannaccone, T., Landucci, G., Scarponi, G. M., Bonvicini, S. and Cozzani, V., 2019. Inherent safety assessment of alternative technologies for LNG ships bunkering. Ocean Engineering, 185(2019):100-114.

IMO, 1977. Resolution A.379(X): establishment of safety zones and fairways or routing systems in offshore exploration areas. International Maritime Organization, London, UK.

IMO, 1989. Resolution A.671(16): safety zones and safety of navigation around offshore installations and structures. International Maritime Organization, London, UK.

IMO, 2015. MSC-MEPC.2/Circ.12/Rev.1: Revised guidelines for formal safety assessment (FSA) for use in the IMO rule-making process. International Maritime Organization, London, UK.

ISO, 2015a. ISO/TS 18683:2015 - Guidelines for systems and installations for supply of LNG as fuel to ships. International Organization for Standardization, Geneva, Switzerland.

ISO, 2015b. ISO/TS 16901:2015 - Guidelines on performing risk assessment in the design of onshore LNG installations including the ship/shore interface. International Organization for Standardization, Geneva, Switzerland.

Jeong, B., Lee, B. S., Zhou, P. and Ha, S., 2018. Determination of safety exclusion zone for LNG bunkering at fuel-supplying point. Ocean Engineering, 152(2018):113-129.

LR, 2017. Guidance notes for technology qualification. Lloyd's Register Group, London, UK.

Mokhatab, S., Mak, J. Y., Valappil, J. V. and Wood, D. A., 2014. Handbook of liquefied natural gas. Elsevier, London, UK.

NOPSEMA, 2016. Guidance notes N04800-GN1695: petroleum safety zones and the area to be 
avoided. National Offshore Petroleum Safety and Environmental Management Authority, Perth, Australia.

OGP, 2010. Risk assessment data directory report No.434-1: process release frequencies. International Association of Oil \& Gas Producers, London, UK.

Paik, J.K. 2019. Advanced structural safety studies with extreme conditions and accidents. Springer, Singapore.

Park, S., Kim, S. K., Kim, S. J. and Paik, J. K., 2019. A preliminary risk Assessment on the development of a small-scaled floating power plant. Journal of Offshore Mechanics and Arctic Engineering, Published Online: Sep. 5, 2019 (https://doi.org/10.1115/1.4044726)

Park, S., Jeong, B., Yoon, J. Y. and Paik, J. K., 2018. A study on factors affecting the safety zone in ship-to-ship LNG bunkering. Ships and Offshore Structures, 13(S1): S312-S321.

Schinas, O. and Butler, M., 2016. Feasibility and commercial considerations of LNG-fueled ships. Ocean Engineering, 122(2016): 84-96.

Seo, S., Chu, B., Noh, Y., Jang, W., Lee, S., Seo, Y. and Chang, D., 2016. An economic evaluation of operating expenditures for LNG fuel gas supply systems onboard ocean-going ships considering availability. Ships and Offshore Structures, 11(S2): S213-S223.

SINTEF, 2015. Offshore and onshore reliability data handbook 2015 - 6th Edition. SINTEF Technology and Society Department of Safety Research, Trondheim Norway.

SGMF, 2018. Recommendation of controlled zones during LNG bunkering. The Society for Gas as a Marine Fuel, London UK.

UK HSE, 1991. Advisory committee on dangerous substances (ACDS): major hazard aspects of the transport of dangerous substances. UK Health and Safety Executive, London, UK.

UK HSE, 2010. Hydrocarbon release database (HCRD). UK Health and Safety Executive, London UK.

UK HSE, 2019. Failure rate and event data for use within risk assessments. UK Health and Safety Executive, London UK.

UK Legislation, 1987. Petroleum act 1987. United Kingdom Legislation, London, UK.

UN, 1958. Convention on the Continental Shelf. United Nations, New York, USA.

Vinnem, J., 2014. Offshore risk assessment. Springer, Berlin, Germany.

$\mathrm{Xu}$, J., Testa, D. and Mukherjee, P. K., 2015. The use of LNG as a marine fuel: The International Regulatory Framework. Ships and Offshore Structures, 46(S3): S225-240. 